\title{
Photoluminescence and Scintillation Properties of Organic- Inorganic Perovskite-type Compounds with Bromophenethylamine
}

\author{
Atsushi Horimoto, ${ }^{1 *}$ Naoki Kawano, ${ }^{1}$ Daisuke Nakauchi, ${ }^{2}$ \\ Hiromi Kimura, ${ }^{2}$ Masaki Akatsuka, ${ }^{2}$ and Takayuki Yanagida ${ }^{2}$ \\ ${ }^{1}$ Graduate School of Engineering Science, Akita University, \\ 1-1 Tegata-Gakuen-machi, Akita 010-8502, Japan \\ ${ }^{2}$ Graduate School of Science and Technology, Nara Institute of Science and Technology (NAIST), \\ 8916-5 Takayama, Ikoma, Nara 630-0192, Japan
}

(Received December 19, 2019; accepted March 23, 2020)

Keywords: scintillator, excitons, quantum well, perovskite, organic-inorganic compounds

(n- $\left.\mathrm{BrC}_{6} \mathrm{H}_{4} \mathrm{C}_{2} \mathrm{H}_{4} \mathrm{NH}_{3}\right)_{2} \mathrm{PbBr}_{4}$ (n-BrPhe) $(n=2,3,4)$ single crystals were synthesized with the aim of enhancing the scintillation light yield of $\left(\mathrm{C}_{6} \mathrm{H}_{5} \mathrm{C}_{2} \mathrm{H}_{4} \mathrm{NH}_{3}\right)_{2} \mathrm{PbBr}_{4}$ (Phe), and their photoluminescence (PL) and scintillation characteristics were evaluated. A sharp PL peak due to the exciton emissions from the inorganic layer was observed at $390-420 \mathrm{~nm}$ in the $n$-BrPhe samples. They had lifetimes of $4.7 \mathrm{~ns}$ (2-BrPhe), $2.1 \mathrm{~ns}$ (3-BrPhe), and $0.9 \mathrm{~ns}$ (4-BrPhe) owing to the exciton recombination in the inorganic layer under $340 \mathrm{~nm}$ excitation. Regarding scintillation, a sharp peak due to exciton emissions from the inorganic layer was detected at 410-440 nm under X-ray irradiation, and the decay time constants under X-ray irradiation were $2.3 \mathrm{~ns}$ (2-BrPhe), $2.0 \mathrm{~ns}$ ( 3 -BrPhe), and $2.1 \mathrm{~ns}$ (4-BrPhe). Moreover, the scintillation light yields under gamma-ray irradiation from ${ }^{241} \mathrm{Am}(59.5 \mathrm{keV})$ were found to be 3100 (2-BrPhe), 2200 (3-BrPhe), and 5900 photons/MeV (4-BrPhe), which were lower than that of Phe (18000 photons/MeV).

\section{Introduction}

A scintillator is a type of phosphor material used in radiation measurements, which have the function of converting high-energy ionizing radiation into several thousands of lowenergy photons (e.g., visible light). ${ }^{(1,2)}$ A scintillator is used for radiation detection in various fields, such as astrophysics, ${ }^{(3)}$ particle physics, ${ }^{(4)}$ well logging, ${ }^{(5)}$ security, ${ }^{(6)}$ and medical imaging. ${ }^{(7)}$ A common scintillator detector for these fields consists of the scintillator phosphor and photodetector, which has the capability to convert low-energy photons into electrons. In general, the basic requirements for the scintillator include chemical stability, radiation hardness, high light yield, fast decay, and high density. ${ }^{(2)}$ There is no scintillator that meets all these requirements for all applications; thus, the optimal material must be selected for each application. Up to now, various scintillators have been available for practical use, such as inorganic single crystals, inorganic ceramics, organic liquids, and plastics.

*Corresponding author: e-mail: m8019225@s.akita-u.ac.jp

https://doi.org/10.18494/SAM.2020.2747 
Among them, inorganic scintillators in the form of a single crystal are often practically used. For example, $\mathrm{NaI}_{\mathrm{Tl}}{ }^{+}$is one of the well-known scintillators with an emission peak approximately at $415 \mathrm{~nm}$ attributable to the $6 \mathrm{p}-6 \mathrm{~s}$ transition of $\mathrm{Tl}^{+}{ }^{(8)}$ It is used in single-photon emission computed tomography (SPECT) owing to its high scintillation intensity, high density, and low cost. ${ }^{(9)}$ Another example of an inorganic scintillator is $\mathrm{CdWO}_{4}$, which shows scintillation due to the charge transfer transitions in $\left(\mathrm{WO}_{4}\right)^{2-}$ with a peak approximately at $470 \mathrm{~nm}^{(10)} \mathrm{CdWO}_{4}$ is used for X-ray computed tomography (CT) owing to its advantages, such as high density and low afterglow level. ${ }^{(9)}$ In addition, $\mathrm{Gd}_{2} \mathrm{SiO}_{5}$ : $\mathrm{Ce}$ is one of the common inorganic scintillators and it exhibits emissions due to the $5 \mathrm{~d}-4 \mathrm{f}$ transitions of $\mathrm{Ce}^{3+}$. $^{(11)}$ It has a high density of $6.7 \mathrm{~g} / \mathrm{cm}^{3}$ and shows moderate scintillation light yield (about 8000 photons $/ \mathrm{MeV}$ ) and a fast decay time constant of about $40 \mathrm{~ns}$; thus, $\mathrm{Gd}_{2} \mathrm{SiO}_{5}$ :Ce is used for positron emission tomography (PET). ${ }^{(12)}$ As mentioned above, many inorganic single-crystal scintillators are applied in various fields. In addition, some materials such as glass scintillators (e.g., Li glass), ${ }^{(13)}$ plastic scintillators (e.g., BC452), ${ }^{(14)}$ organic liquid scintillators (e.g., BC505), ${ }^{(15)}$ and ceramic scintillators (e.g., $\left.\mathrm{Gd}_{2} \mathrm{O}_{2} \mathrm{~S}: \mathrm{Pr}\right)^{(16)}$ are also used in practice.

Unlike the above scintillators, we have been developing organic-inorganic perovskite-type compounds for scintillator applications. Organic-inorganic layered perovskite-type compounds, $\left(\mathrm{RNH}_{3}\right)_{2} \mathrm{PbX}_{4}$ ( $\mathrm{R}$ : hydrocarbon group, $\mathrm{X}$ : halogen), have a self-organized multiple quantum well structure where the organic layer is regarded as a barrier layer and the inorganic layer is regarded as a well layer. ${ }^{(17,18)}$ In the compounds, excitons are formed in the inorganic layer, and the compounds show efficient scintillation with a short decay time due to the quantum confinement effect. In particular, $\left(\mathrm{C}_{6} \mathrm{H}_{5} \mathrm{C}_{2} \mathrm{H}_{4} \mathrm{NH}_{3}\right)_{2} \mathrm{PbBr}_{4}$ (Phe) shows a high light yield (about 14000 photons $/ \mathrm{MeV}$ ) under gamma-ray irradiation from ${ }^{137} \mathrm{Cs}$ and a fast scintillation decay (about $11 \mathrm{~ns}$ ) under X-ray irradiation. ${ }^{(19)}$ Owing to the high scintillation light yield and short decay time due to the quantum confinement effect, the use of organic-inorganic layered perovskitetype compounds in PET and synchrotron radiation facilities is considered.

In this study, we synthesized $\left(n-\mathrm{BrC}_{6} \mathrm{H}_{4} \mathrm{C}_{2} \mathrm{H}_{4} \mathrm{NH}_{3}\right)_{2} \mathrm{PbBr}_{4}(n=2,3,4)$ single crystals to increase the scintillation light yield of $\left(\mathrm{C}_{6} \mathrm{H}_{5} \mathrm{C}_{2} \mathrm{H}_{4} \mathrm{NH}_{3}\right)_{2} \mathrm{PbBr}_{4}$. Single-crystal structural analysis has demonstrated that $\mathrm{Phe}$ has geometric distortion in the $\mathrm{Br}-\mathrm{Pb}-\mathrm{Br}$ bonds inside the $\mathrm{PbBr}_{6}{ }^{4-}$ octahedron and the $\mathrm{Pb}-\mathrm{Br}-\mathrm{Pb}$ bonds between adjacent $\mathrm{PbBr}_{6}{ }^{4-}$ octahedra, and these geometric distortions result in the increase in photoluminescence (PL) and scintillation intensities since the distortion leads to an increase in the exciton mass and a decrease in the exciton Bohr radius. ${ }^{(20)}$ In addition, it has been reported that the substitution of a bromine $(\mathrm{Br})$ atom on the benzene ring of $\left(\mathrm{C}_{6} \mathrm{H}_{5} \mathrm{C}_{2} \mathrm{H}_{4} \mathrm{NH}_{3}\right)_{2} \mathrm{SnI}_{4}$ leads to a decrease in the $\mathrm{Sn}-\mathrm{I}-\mathrm{Sn}$ bond angle between adjacent $\mathrm{SnI}_{6}{ }^{4-}$ octahedra. ${ }^{(21)}$ Therefore, $\left(n-\mathrm{BrC}_{6} \mathrm{H}_{4} \mathrm{C}_{2} \mathrm{H}_{4} \mathrm{NH}_{3}\right)_{2} \mathrm{PbBr}_{4}(n=2,3,4)$ could exhibit a more efficient scintillation than Phe because the geometric distortion in the inorganic layer could be further induced by the $\mathrm{Br}$ substitution on the benzene ring. After the synthesis of the single crystals, their PL and scintillation properties were investigated.

\section{Experimental Methods}

$2-\mathrm{Br} \mathrm{C}_{6} \mathrm{H}_{4} \mathrm{C}_{2} \mathrm{H}_{4} \mathrm{~N} \mathrm{H}_{2}$ (2-bromo phenethyla m ine), 3 - $\mathrm{B} \mathrm{r} \mathrm{C}_{6} \mathrm{H}_{4} \mathrm{C}_{2} \mathrm{H}_{4} \mathrm{~N} \mathrm{H}_{2}$ (3-bromophenethylamine), 4- $\mathrm{BrC}_{6} \mathrm{H}_{4} \mathrm{C}_{2} \mathrm{H}_{4} \mathrm{NH}_{2}$ (4-bromophenethylamine), and 
$\mathrm{C}_{6} \mathrm{H}_{5} \mathrm{C}_{2} \mathrm{H}_{4} \mathrm{NH}_{2}$ (phenethylamine) were used as organic precursors. Stoichiometric quantities of each precursor and $\mathrm{HBr}$ were dissolved in $\mathrm{N}, \mathrm{N}$-dimethylformamide (DMF) and mixed for $1 \mathrm{~h}$. After solvent evaporation, $n-\mathrm{BrC}_{6} \mathrm{H}_{4} \mathrm{C}_{2} \mathrm{H}_{4} \mathrm{NH}_{3} \mathrm{Br}(n=2,3,4)$ and $\mathrm{C}_{6} \mathrm{H}_{5} \mathrm{C}_{2} \mathrm{H}_{4} \mathrm{NH}_{3} \mathrm{Br}$ powders were obtained. Subsequently, each powder and $\mathrm{PbBr}_{2}$ in a molar ratio of 2:1 were mixed in DMF and stirred for $3 \mathrm{~h}$. Finally, (2- $\left.\mathrm{BrC}_{6} \mathrm{H}_{4} \mathrm{C}_{2} \mathrm{H}_{4} \mathrm{NH}_{3}\right)_{2} \mathrm{PbBr}_{4}$ (2-BrPhe), (3- $\left.\mathrm{BrC}_{6} \mathrm{H}_{4} \mathrm{C}_{2} \mathrm{H}_{4} \mathrm{NH}_{3}\right)_{2} \mathrm{PbBr}_{4}$ (3-BrPhe), (4- $\left.\mathrm{BrC}_{6} \mathrm{H}_{4} \mathrm{C}_{2} \mathrm{H}_{4} \mathrm{NH}_{3}\right)_{2} \mathrm{PbBr}_{4}$ (4-BrPhe), and $\left(\mathrm{C}_{6} \mathrm{H}_{5} \mathrm{C}_{2} \mathrm{H}_{4} \mathrm{NH}_{3}\right)_{2} \mathrm{PbBr}_{4}$ (Phe) powders were obtained by evaporating the solvent. Furthermore, single crystals of the above compounds were prepared as follows. The powders were dissolved in DMF in a glass bottle, and then nitromethane was added until the compounds precipitated. Then, the precipitate solution in the glass bottle was completely dissolved at $90{ }^{\circ} \mathrm{C}$, and the glass bottle was placed at $90{ }^{\circ} \mathrm{C}$ in a liquid-phase organic synthesizer (Chemi Chemi-300, Sibata). Finally, the single crystals were obtained by decreasing the temperature gradually from $90{ }^{\circ} \mathrm{C}$ to room temperature at a rate of $3.5^{\circ} \mathrm{C} / \mathrm{h}$.

To evaluate the crystal structure of the obtained samples, the X-ray diffraction (XRD) patterns were measured using an X-ray diffractometer (RINT2000, Rigaku) with the $2 \theta$ range of 3 to $30^{\circ}$ at room temperature under $\mathrm{Cu} \mathrm{K} \alpha$ radiation. Regarding the PL property, PL excitation/ emission contour graphs and PL quantum efficiency (QE) were measured using a PL QE spectrometer (Quantaurus-QY C11347, Hamamatsu). The measurement interval of excitation wavelength was $10 \mathrm{~nm}$. PL decay curves were obtained using a compact fluorescence lifetime spectrometer (Quantaurus-tau C11367, Hamamatsu). In these measurements, the excitation wavelength was $340 \mathrm{~nm}$. As a scintillation property, scintillation spectra were evaluated at room temperature under X-ray irradiation generated by an X-ray generator (XRB80N100, Spellman). To avoid direct X-ray exposure to CCD (Newton 920, Andor), the spectrometer was placed off the irradiation axis, and the scintillation light was guided into the spectrometers through a $2 \mathrm{~m}$ optical fiber. Scintillation decay curves were measured using the afterglow system, which was our original setup. The details of the instrument could be found elsewhere. ${ }^{(22)}$ Furthermore, the pulse height spectra were measured for the evaluation of scintillation light yield under gamma-ray irradiation from ${ }^{241} \mathrm{Am}$. Here, the setup consisted of a multichannel analyzer (Pocket MCA, Amptec), a photomultiplier tube (R7600-U200, Hamamatsu), a shaping amplifier (Model 570, ORTEC), and a preamplifier (Model 113, ORTEC).

\section{Results and Discussion}

\subsection{Sample characterization}

Figure 1 illustrates photographs of $n$ - $\mathrm{BrPhe}(n=2,3,4)$ and Phe single crystals. The diameter of the samples was about $5 \mathrm{~mm}$. $n$-BrPhe was not so transparent that the line pattern on the back of the samples was not clearly observed, while Phe looked transparent.

Figure 2 shows the XRD patterns of the $n$-BrPhe $(n=2,3,4)$ and Phe single crystals. All the samples showed several diffraction patterns over the $2 \theta$ range of $3-30^{\circ}$. Compared with previous studies, these peaks of the samples were confirmed to be $(002 l)(l=1,2,3,4,5,6,7){ }^{(19)}$ The observed diffraction peaks suggested that all the samples formed two-dimensional quantum well structures. Furthermore, the c-axis lattice constant of each sample was estimated to be 

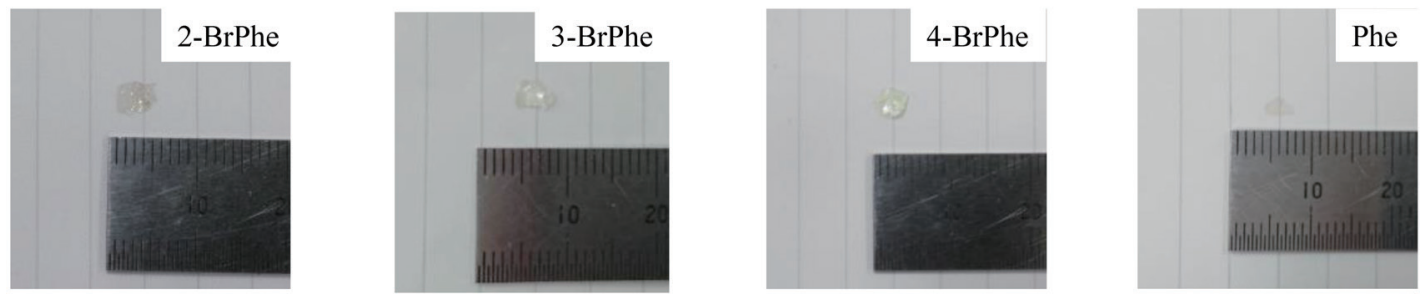

Fig. 1. Photographs of $n$-BrPhe $(n=2,3,4)$ and Phe single crystals.
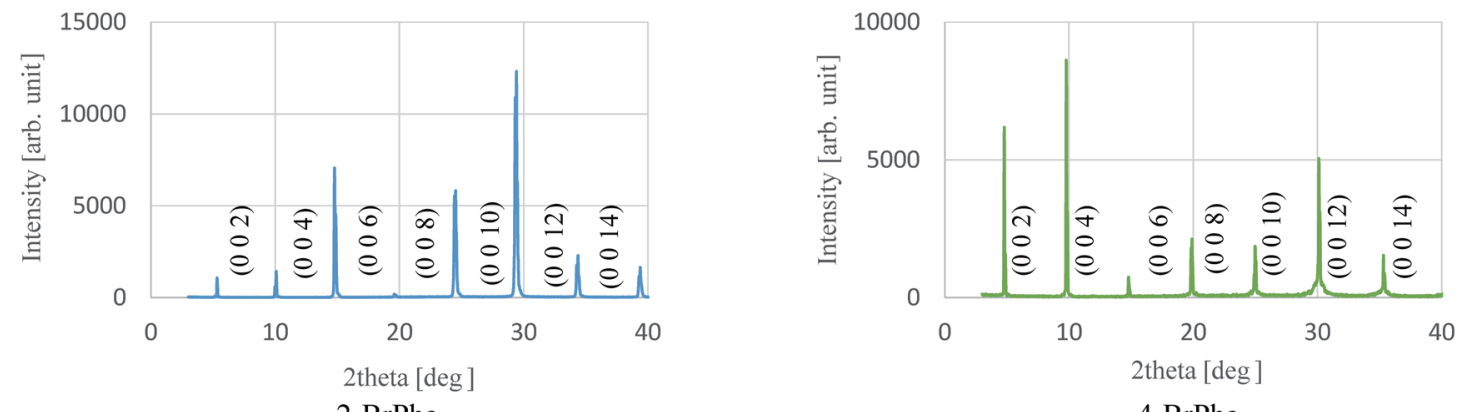

2-BrPhe
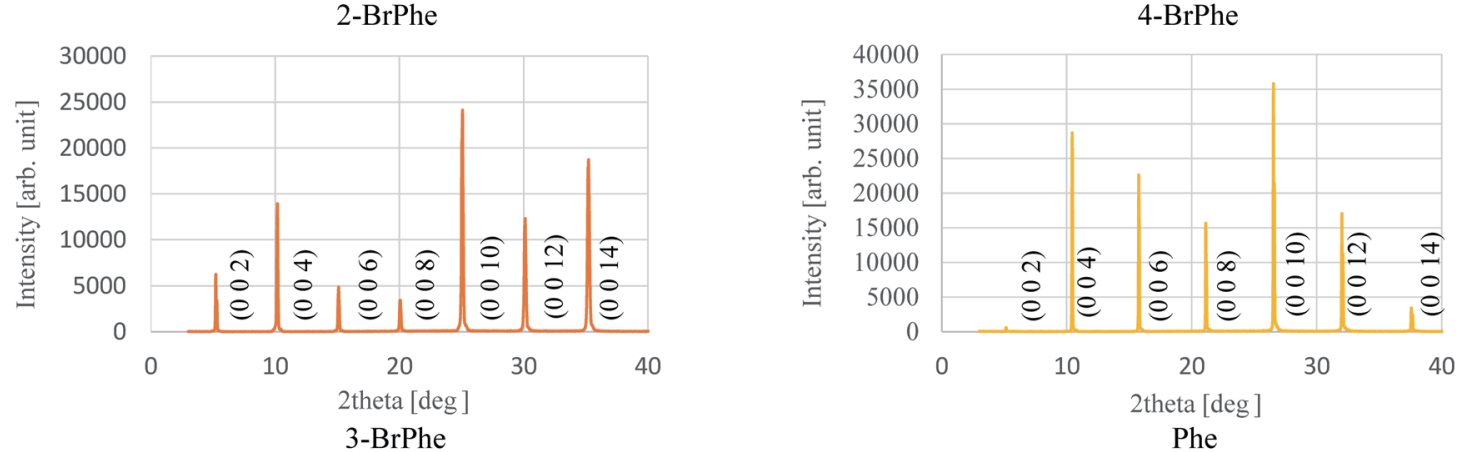

Fig. 2. (Color online) XRD patterns of $n$-BrPhe $(n=2,3,4)$ and Phe single crystals.

18.3 (2-BrPhe), 17.6 (3-BrPhe), 17.5 (4-BrPhe), and $16.4 \AA$ (Phe). The c-axis lattice constant of Phe was found to be different from that of $n$-BrPhe $(n=2,3,4)$, suggesting that the structure of the organic and inorganic layers might change with the incorporation of $\mathrm{Br}$ on the benzene ring. In addition, the intensity of the diffraction peaks for $n$-BrPhe was found to be lower than that for Phe.

\subsection{PL properties}

Figure 3 shows the PL emission and excitation contour graphs of $n$-BrPhe $(n=2,3,4)$ and Phe single crystals. 2-BrPhe showed emissions with peaks at approximately 390 and $410 \mathrm{~nm}$, whereas 3-BrPhe, 4-BrPhe, and Phe exhibited emission peaks at approximately 410 and $430 \mathrm{~nm}$. From the comparison of Phe emission, we inferred that the peaks at $390 \mathrm{~nm}$ (2-BrPhe) and $410 \mathrm{~nm}$ (3-BrPhe and 4-BrPhe) were derived from the free exciton recombination in the 

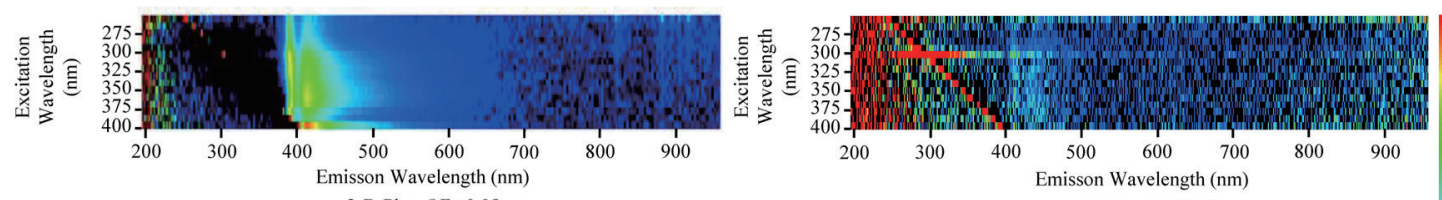

2-BrPhe $Q E=0.08$

4-BrPhe $Q E=0.01$
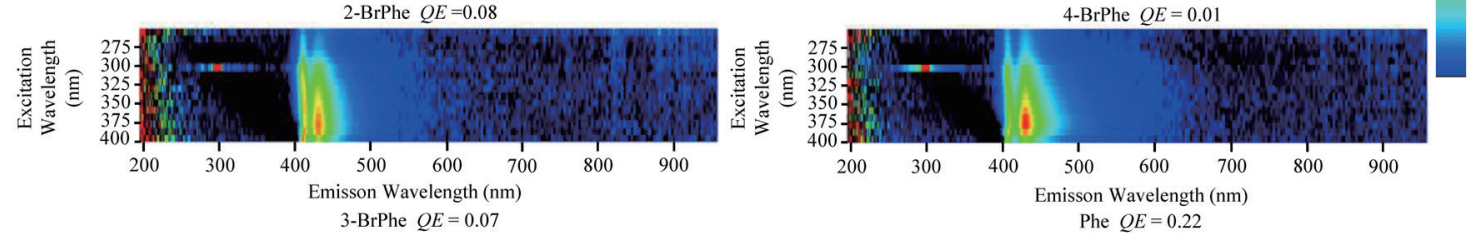

Fig. 3. (Color online) PL emission and excitation contour graphs of $n$-BrPhe $(n=2,3,4)$ and Phe single crystals.

inorganic layer, and the peaks at $410 \mathrm{~nm}$ (2-BrPhe) and $430 \mathrm{~nm}$ (3-BrPhe and 4-BrPhe) might originate from exciton recombination at a shallow trap. ${ }^{(23-26)}$ Furthermore, QE values across $390-600 \mathrm{~nm}$ at an excitation wavelength of $340 \mathrm{~nm}$ were 0.08 (2-BrPhe), 0.07 (3-BrPhe), 0.01 (4-BrPhe), and 0.22 (Phe). Therefore, QE values were decreased by the $\mathrm{Br}$ substitution on the benzene ring.

Figure 4 shows the PL decay curves of $n$-BrPhe $(n=2,3,4)$ and Phe single crystals. The monitoring wavelength was around $400 \mathrm{~nm}$, whereas the excitation wavelength was $340 \mathrm{~nm}$. The decay curves of the samples were approximated by the sum of two exponential decay functions. The obtained decay time constants of the first component were $4.7 \mathrm{~ns}$ (2-BrPhe), $2.1 \mathrm{~ns}$ (3-BrPhe), $0.9 \mathrm{~ns}$ (4-BrPhe), and $4.7 \mathrm{~ns}$ (Phe), and the decay time constants became lower for the $n$-BrPhe than for the Phe with the incorporation of $\mathrm{Br}$ on the benzene ring. Furthermore, the decay time constants of the second components were $9.4 \mathrm{~ns}$ (2-BrPhe), $7.5 \mathrm{~ns}$ (3-BrPhe), $2.7 \mathrm{~ns}$ (4-BrPhe), and $14.0 \mathrm{~ns}$ (Phe). The second component could be ascribed to excitons trapped at the shallow trap in the inorganic layer. ${ }^{(23,26)}$

To investigate the cause of the change in PL characteristics due to the $\mathrm{Br}$ substitution on the benzene ring, we calculated the radiative and nonradiative decay rates. QE $(\Phi)$ and PL decay time $(\tau)$ can be expressed by the following equations using the radiative decay rate $\left(k_{f}\right)$ and nonradiative decay rate $\left(k_{n r}\right)$.

$$
\begin{gathered}
\Phi=k_{f} /\left(k_{f}+k_{n r}\right) \\
\tau=1 /\left(k_{f}+k_{n r}\right)
\end{gathered}
$$

From these equations, $k_{f}$ and $k_{n r}$ can be expressed as follows.

$$
\begin{gathered}
k_{f}=\tau^{-1} \cdot \Phi \\
k_{n r}=k_{f} \cdot\left(\Phi^{-1}-1\right)
\end{gathered}
$$

Table 1 summarizes the radiative and nonradiative decay rates of the $n$-BrPhe $(n=2,3,4)$ and Phe single crystals. Here, the QE and decay time constant of free excitons were used for 

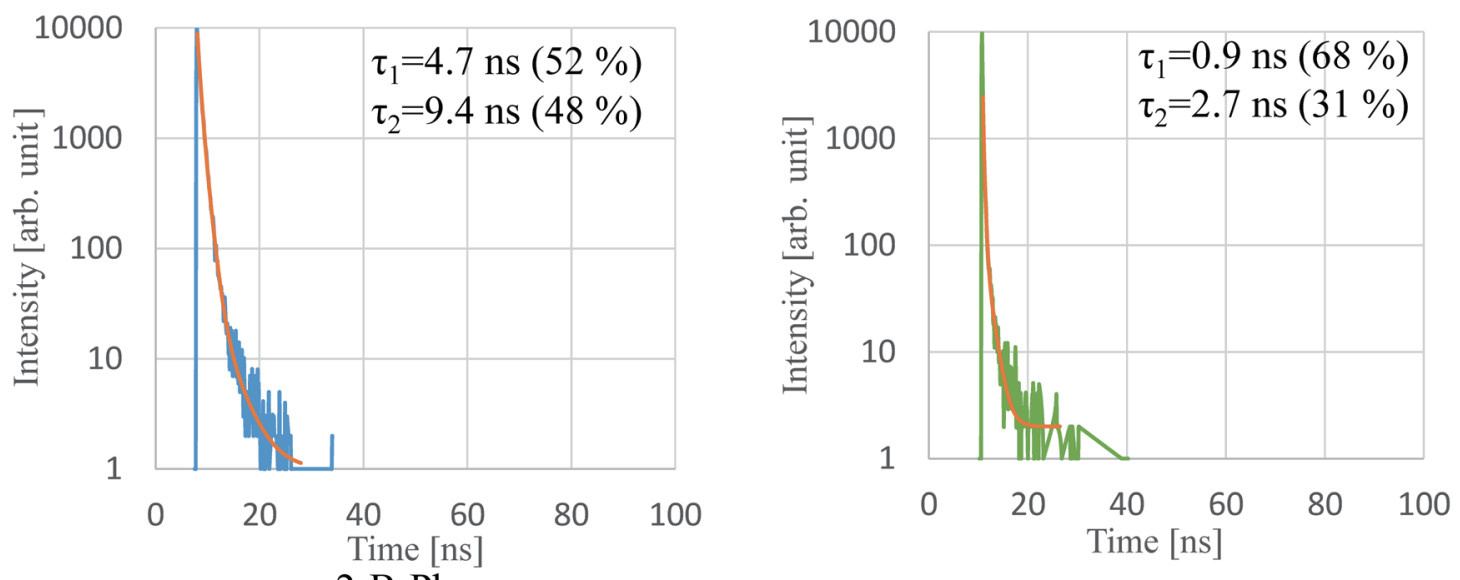

2-BrPhe

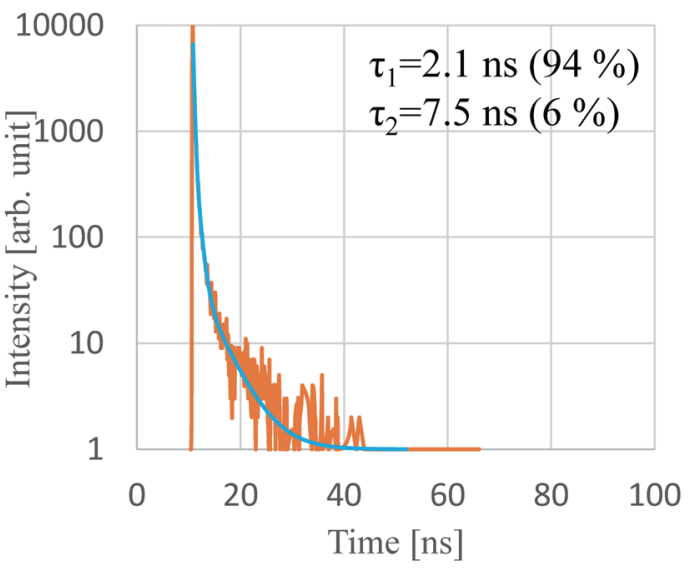

3-BrPhe

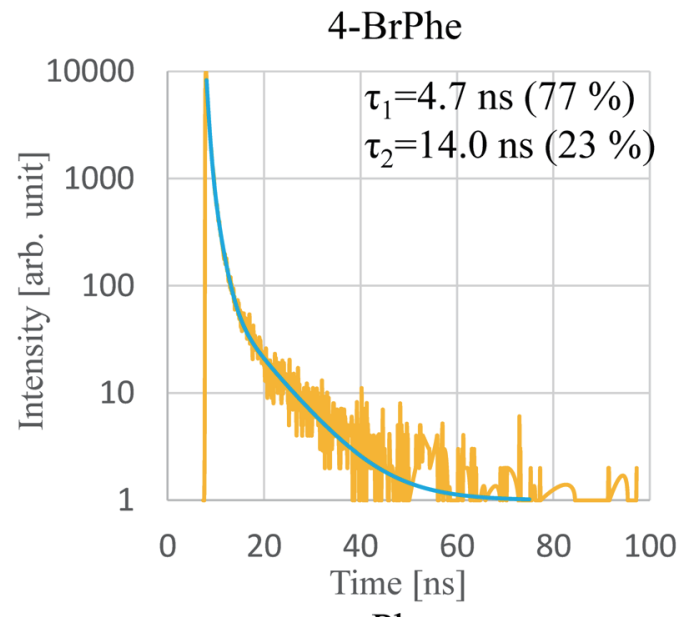

Phe

Fig. 4. (Color online) PL decay curves of $n$ - $\operatorname{BrPhe}(n=2,3,4)$ and Phe single crystals.

Table 1

Radiative and nonradiative decay rates of $n$ - $\mathrm{BrPhe}(n=2,3,4)$ and Phe single crystals.

\begin{tabular}{lcccc}
\hline & $\left(\mathrm{C}_{6} \mathrm{H}_{5} \mathrm{C}_{2} \mathrm{H}_{4} \mathrm{NH}_{3}\right)_{2} \mathrm{PbBr}_{4}$ & \multicolumn{3}{c}{$\left(n-\mathrm{C}_{6} \mathrm{H}_{4} \mathrm{C}_{2} \mathrm{H}_{4} \mathrm{NH}_{3}\right)_{2} \mathrm{PbBr}_{4}$} \\
\cline { 3 - 5 } & $(\mathrm{Phe})$ & $2-\mathrm{BrPhe}$ & $3-\mathrm{BrPhe}$ & $4-\mathrm{BrPhe}$ \\
\hline$k_{f}\left(10^{6} \mathrm{~s}^{-1}\right)$ & 8.3 & 2.3 & 6.7 & 7.8 \\
$k_{n r}\left(10^{8} \mathrm{~s}^{-1}\right)$ & 2.0 & 2.1 & 3.6 & 11.0 \\
$\tau(\mathrm{ns})$ & 4.7 & 4.7 & 2.1 & 0.9 \\
\multirow{2}{*}{ QE of free exciton emissions ( - ) } & 0.039 & 0.011 & 0.018 & 0.007 \\
& $(400-420 \mathrm{~nm})$ & $(385-400 \mathrm{~nm})$ & $(400-425 \mathrm{~nm})$ & $(390-420 \mathrm{~nm})$ \\
\hline
\end{tabular}

the calculation. Among the samples tested, Phe showed the highest radiative decay rate, and the radiative decay rate was decreased by the $\mathrm{Br}$ substitution on the benzene ring. Previous studies have shown that the exciton properties of the inorganic layers depend on the bond angles of $\mathrm{Pb}-\mathrm{Br}-\mathrm{Pb}$ and $\mathrm{Br}-\mathrm{Pb}-\mathrm{Br}$ in the inorganic layers. The decrease in the radiative decay rate of the $n$-BrPhe suggests that further structural distortion in the inorganic layer might not be induced by the $\mathrm{Br}$ substitution. Furthermore, the nonradiative decay rate increased with the 
$\mathrm{Br}$ incorporation on the benzene ring, and the nonradiative decay rate of the 4-BrPhe was the highest. In the organic-inorganic layered perovskite-type compounds, the crystal structure is self-organized by the van der Waals interaction and Coulomb interaction. These results suggest that one of the causes of the increase in the nonradiative decay rate might be the decrease in crystal quality owing to the $\mathrm{Br}$ substitution on the benzene ring because the intensity of the diffraction peaks in Fig. 2 decreased owing to the Br substitution.

\subsection{Scintillation properties}

Figure 5 shows the X-ray-induced scintillation spectra of $n$-BrPhe $(n=2,3,4)$ and Phe single crystals. A sharp peak was observed at approximately $410 \mathrm{~nm}$ for 2-BrPhe and at approximately $440 \mathrm{~nm}$ for 3-BrPhe, 4-BrPhe, and Phe. Compared with the previous study, the sharp peaks could be attributed to exciton emissions from the inorganic layer. ${ }^{(19)}$

Figure 6 shows the X-ray-induced scintillation decay curves of $n$-BrPhe $(n=2,3,4)$ and Phe single crystals. These decay curves of the samples were approximated using two exponential decay functions. The faster components of the scintillation decay time were $2.3 \mathrm{~ns}$ (2-BrPhe), $2.0 \mathrm{~ns}$ (3-BrPhe), $2.1 \mathrm{~ns}$ (4-BrPhe), and $5.3 \mathrm{~ns}$ (Phe). The component should originate from the recombination of excitons in the inorganic layer shown in the previous study. ${ }^{(19)}$ These decay time constants of $n$ - $\mathrm{BrPhe}(n=2,3,4)$ were found to be higher than that of Phe. In addition, the slower components were $13.2 \mathrm{~ns}$ (2-BrPhe), $9.6 \mathrm{~ns}$ (3-BrPhe), 9.2 ns (4-BrPhe), and $28.3 \mathrm{~ns}$ (Phe). These components may be due to the recombination of trapped excitons in the inorganic layer. These decay time constants of the faster component in scintillation were comparable to those in PL.

Figure 7 shows the pulse-height spectra of $n$-BrPhe $(n=2,3,4)$, Phe, and $\mathrm{Gd}_{2} \mathrm{SiO}_{5}$ : $\mathrm{Ce}$ (GSO:Ce) single crystals obtained using the ${ }^{241} \mathrm{Am}$ gamma-ray source $(59.5 \mathrm{keV})$. GSO:Ce (10000 photons $/ \mathrm{MeV})$ was selected as the reference for the evaluation of scintillation light yield. $^{(27)}$ The samples showed a clear pulse height peak, and each channel number was found to be 68 (2-BrPhe), 48 (3-BrPhe), 130 (4-BrPhe), 220 (GSO:Ce), and 401 (Phe). On the assumption

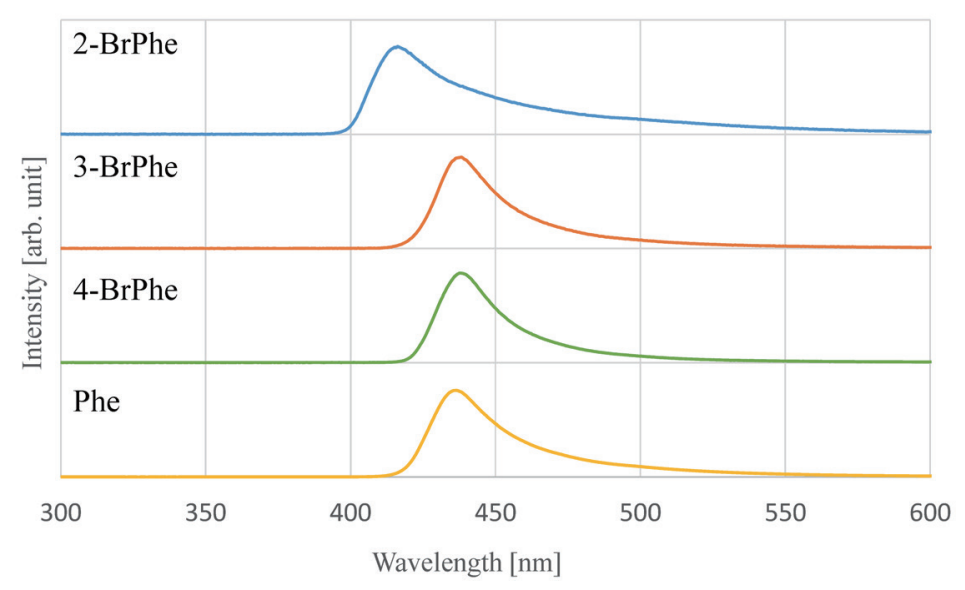

Fig. 5. (Color online) X-ray-induced scintillation spectra of $n$-BrPhe $(n=2,3,4)$ and Phe single crystals. 

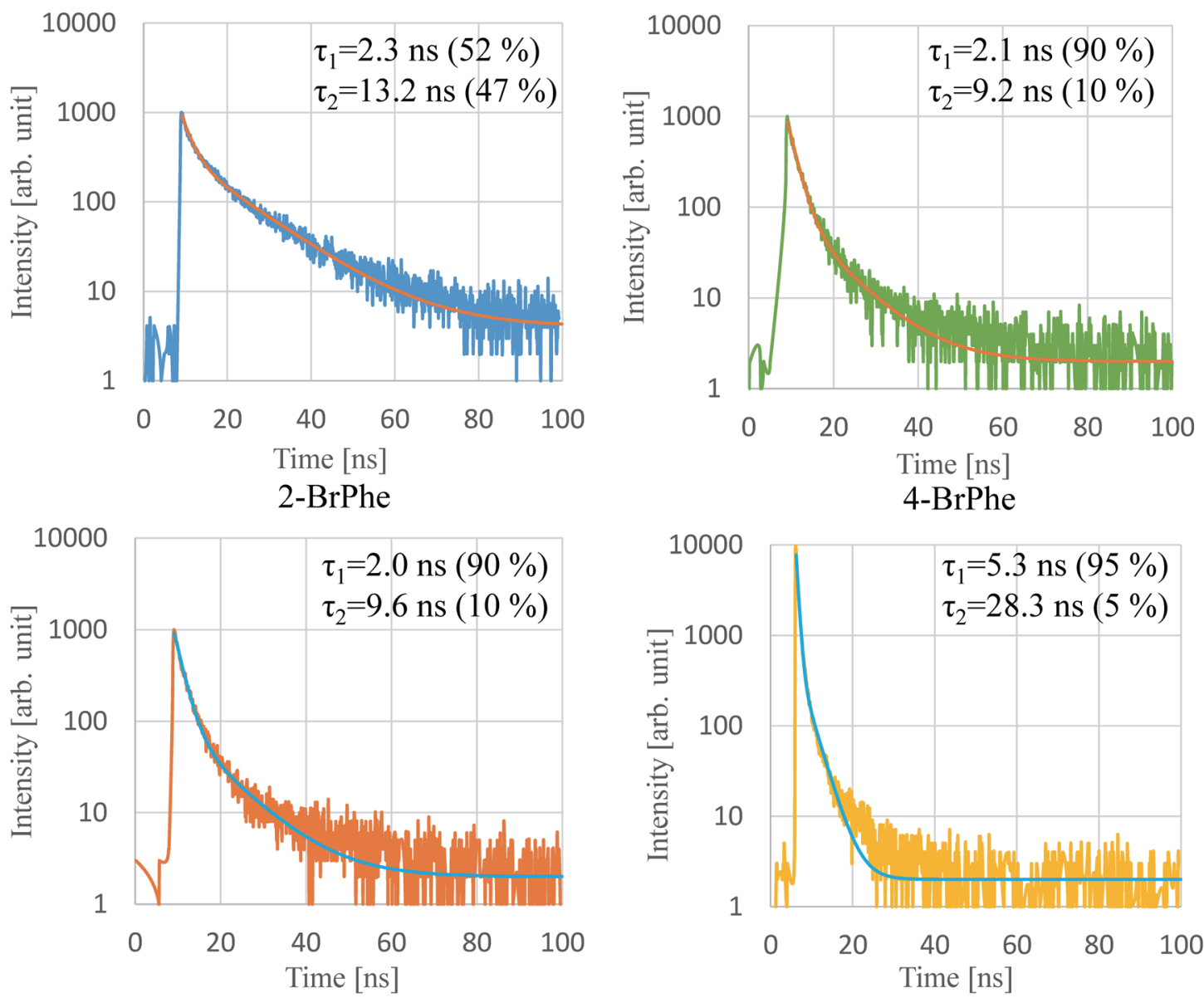

3-BrPhe

Phe

Fig. 6. (Color online) X-ray-induced scintillation decay curves of $n$-BrPhe $(n=2,3,4)$ and Phe single crystals.

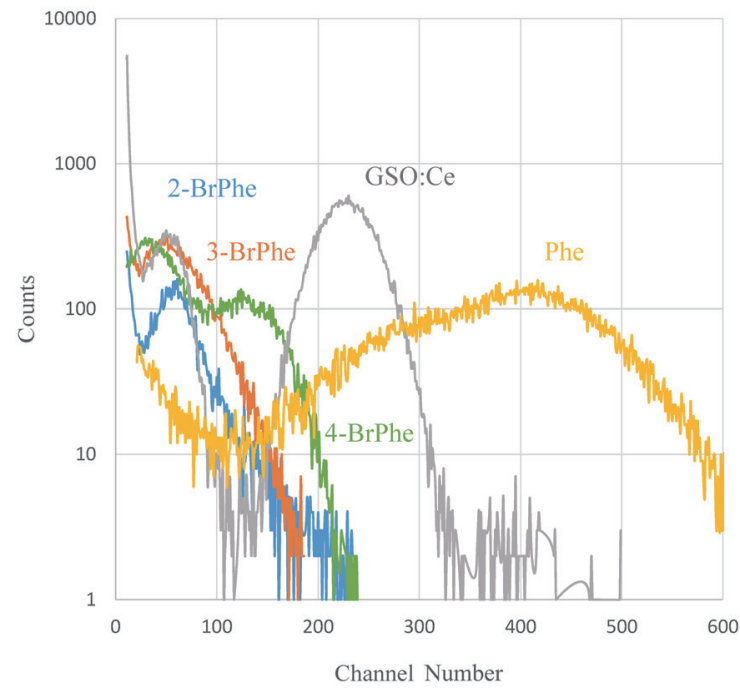

Fig. 7. (Color online) Pulse-height spectra of $n$ - $\mathrm{BrPhe}(n=2,3,4)$, Phe, and $\mathrm{Gd}_{2} \mathrm{SiO}_{5}$ :Ce (GSO:Ce) single crystals obtained using ${ }^{241}$ Am gamma-ray source $(59.5 \mathrm{keV})$. 
that the scintillation light yield is proportional to the channel number, the scintillation light yields were estimated to be approximately 3100 (2-BrPhe), 2200 (3-BrPhe), 5900 (4-BrPhe), and 18000 photons $/ \mathrm{MeV}$ (Phe). $n$-BrPhe showed a lower scintillation light yield than Phe, and the results were consistent with the QE values shown in Fig. 3. These results suggest that scintillation intensity cannot be enhanced by the substitution of $\mathrm{Br}$ on the benzene ring as well as $\mathrm{QE}$ values. In this study, the $\mathrm{PL}$ and scintillation properties of $\left(n-\mathrm{BrC}_{6} \mathrm{H}_{4} \mathrm{C}_{2} \mathrm{H}_{4} \mathrm{NH}_{3}\right)_{2} \mathrm{PbBr}_{4}$ $(n=2,3,4)$ and $\left(\mathrm{C}_{6} \mathrm{H}_{5} \mathrm{C}_{2} \mathrm{H}_{4} \mathrm{NH}_{3}\right)_{2} \mathrm{PbBr}_{4}$ were investigated for the development of fastresponse scintillators. The scintillation light yield was decreased by the $\mathrm{Br}$ substitution on the benzene ring, and the decay time constant also decreased. In future studies, it is necessary to incorporate another substituent on the benzene ring and evaluate the scintillation properties to enhance the scintillation properties of $\left(\mathrm{C}_{6} \mathrm{H}_{5} \mathrm{C}_{2} \mathrm{H}_{4} \mathrm{NH}_{3}\right)_{2} \mathrm{PbBr}_{4}$. Furthermore, it should be important to investigate in detail the effects of halogen substituents including $\mathrm{Br}$ on the basic exciton properties and crystal structures.

\section{Conclusion}

We synthesized $\left(n-\mathrm{BrC}_{6} \mathrm{H}_{4} \mathrm{C}_{2} \mathrm{H}_{4} \mathrm{NH}_{3}\right)_{2} \mathrm{PbBr}_{4}(n=2,3,4)$ and $\left(\mathrm{C}_{6} \mathrm{H}_{5} \mathrm{C}_{2} \mathrm{H}_{4} \mathrm{NH}_{3}\right)_{2} \mathrm{PbBr}_{4}$ single crystals and evaluated their PL and scintillation properties. All the samples showed PL peaks at approximately $390-440 \mathrm{~nm}$ owing to exciton recombination in the inorganic layer, while they exhibited exciton emissions with a peak at approximately $410-440 \mathrm{~nm}$ under X-ray irradiation. In addition, the decay time constants in PL and scintillation were on the order of several nanoseconds, which is typical for the exciton emissions in the inorganic layer. Moreover, the scintillation light yields under gamma-ray irradiation from ${ }^{241} \mathrm{Am}$ were estimated to be about 3100 (2-BrPhe), 2200 (3-BrPhe), and 5900 photons/MeV (4-BrPhe), which were lower than that of Phe (18000 photons/MeV).

\section{Acknowledgments}

This work was supported by a Grant-in-Aid for Research Activity Start-up (17H06867) from the Ministry of Education, Culture, Sports, Science and Technology of Japan (MEXT).

\section{References}

1 C. W. E. Eijk: Nucl. Instrum. Methods Phys. Res., Sect. A 460 (2001) 1.

2 S. E. Derenzo, M. J. Weber, E. Bourret-Courchesne, and M. K. Klintenberg: Nucl. Instrum. Methods Phys. Res., Sect. A 505 (2003) 111.

3 T. Itoh, T. Yanagida, M. Kokubun, M. Sato, R. Miyawaki, K. Makishima, T. Takashima, T. Tanaka, K. Nakazawa, T. Takahashi, N. Shimura, and H. Ishibashi: Nucl. Instrum. Methods Phys. Res., Sect. A 579, (2007) 239.

4 T. Itoh, M. Kokubun, T. Takashima, T. Honda, K. Makishima, T. Tanaka, T. Yanadiga, S. Hirakuri, R. Miyawaki, H. Takahashi, K. Nakazawa, and T. Takahashi: IEEE Trans. Nucl. Sci. 53 (2006) 2983.

5 T. Yanagida, Y. Fujimoto, S. Kurosawa, K. Kamada, H. Takahashi, Y. Fukazawa, M. Nik1, and V. Chan: Jpn. J. Appl. Phys. 52 (2013) 076401.

6 D. Totsuka, T. Yanagida, K. Fukuda, N. Kawaguchi, Y. Fujimoto, J. Pejchal, Y. Yokota, and A. Yoshikawa: Nucl. Instrum. Methods Phys. Res., Sect. A 659 (2011) 399.

7 M. Akatsuka, Y. Usui, D. Nakauchi, G. Okada, N. Kawaguchi, and T. Yanagida: Sens. Mater. 30 (2018) 1525. 
8 R. Hofstadter: Phys. Rev. 74 (1948) 100.

9 W. W. Moses: SCINT99, Lawrence Berkeley National Laboratory (1999) LBNL-4580.

10 S. E. Derenzo, M. J. Weber, W. E. Bourret-Courchesne, and M. K. Klintenberg: Nucl. Instrum. Methods Phys. Res., Sect. A 505 (2003) 111.

11 C. W. E. Eijk: Nucl. Instrum. Methods Phys. Res., Sect. A 392 (1997) 285.

12 H. Murayama, I. Ishibashi, H. Uchida, T. Omura, and T. Yamashita: IEEE NS-45 (1998) 1152.

13 M. Katagiri, K. Sakasai, M. Matsubayashi, T. Nakamura, Y. Kondo, Y. Chujo, H. Nanto, and T. Kojima: Nucl. Instrum. Methods Phys. Res., Sect. A 529 (2004) 274.

14 Data sheet of BC452: https://www.crystals.saint-gobain.com/sites/imdf.crystals.com/files/documents/bc452data-sheet.pdf (BC452 is equivalent to NE142).

15 Data sheet of BC505: https://www.crystals.saint-gobain.com/sites/imdf.crystals.com/files/documents/bc505data-sheet.pdf.

16 C. D. Greskovich and D. Cusano: Annu. Rev. Mater. Sci. 27 (1997) 69.

17 D. B. Mitzi: Chem. Mater. 8 (1996) 791.

18 K. Shibuya, M. Koshimizu, Y. Takeoka, and K. Asai: Nucl. Instrum. Methods Phys. Res., Sect. B 194 (2002) 207.

19 N. Kawano, M. Koshimizu, G. Okada, Y. Fujimoto, N. Kawaguchi, T. Yanagida, and K. Asai: Sci. Rep. 7 (2017) 14754.

20 N. Kawano, M. Koshimizu, Y. Sun, N. Yahaba, Y. Fujimoto, T. Yanagida, and K. Asai: J. Phys. Chem. C 118 (2014) 9101.

21 Z. T. Xu, D. B. Mitzi, C.D. Dimitrakopoulos, and K. R. Maxcy: Inorg. Chem. 42 (2003) 2031.

22 T. Yanagida, K. Kamada, Y. Fujimoto, H. Yagi, and T. Yanagitani: Opt. Mater. 35 (2013) 24802.

23 K. Shibuya, M. Koshimizu, H. Murakami, Y. Muroya, Y. Katsumura, and K. Asai: Jpn. J. Appl. Phys. 43 (2004) L1333.

24 N. Kawano, M. Koshimizu, Y. Sun, N. Yahaba, Y. Fujimoto, T. Yanagida, and K. Asai: Jpn. J. Appl. Phys. 53 (2014) 02BC20.

25 N. Kawano, M. Koshimizu, A. Horiai, F. Nishikido, R. Haruki, S. Kishimoto, K. Shibuya, Y. Fujimoto, T. Yanagida, and K. Asai: Jpn. J. Appl. Phys. 55 (2016) 110309.

26 N. Kawano, M. Koshimizu, G Okada, Y. Fujimoto, N. Kawaguchi, T. Yanagida, and K. Asai: Jpn. J. Appl. Phys. 57 (2018) 02CA03.

27 M. Sato, T. Yanagida, A. Yoshikawa, Y. Yatsu, J. Kataoka, Y. Ishikawa, and F. Saito: IEEE NSS MIC 2007, Conf. Record. N37-2 (2007) 2023. 